\title{
Education Research: Variation in priorities for neurocritical care education expressed across role groups
}

\author{
Abigail S. Cohen, BA, * Saef Izzy, MD,* Monisha A. Kumar, MD, Cara J. Joyce, PhD, Stephen A. Figueroa, MD, \\ Matthew B. Maas, MD, Christiana E. Hall, MD, David L. McDonagh, MD, David P. Lerner, MD, \\ Paul M. Vespa, MD, Lori A. Shutter, MD, and Eric S. Rosenthal, MD
}

Neurology ${ }^{\circledR}$ 2018;90:1117-1122. doi:10.1212/WNL.0000000000005682

\author{
Correspondence \\ Dr. Rosenthal \\ erosenthal@ \\ mgh.harvard.edu
}

\begin{abstract}
Objective

To define expectations for neurocritical care (NCC) core competencies vs competencies considered within the domain of other subspecialists.

\section{Methods}

An electronic survey was disseminated nationally to NCC nurses, physicians, fellows, and neurology residents through Accreditation Council for Graduate Medical Education neurology residency program directors, United Council for Neurologic Subspecialties neurocritical care fellowship program directors, and members of the Neurocritical Care Society.
\end{abstract}

\section{Results}

A total of 268 neurocritical care providers and neurology residents from 30 institutions responded. Overall, $>90 \%$ supported NCC graduates independently interpreting and managing systemic and cerebral hemodynamic data, or performing brain death determination, neurovascular ultrasound, vascular access, and airway management. Over $75 \%$ endorsed that NCC graduates should independently interpret EEG and perform bronchoscopies. Fewer but substantial respondents supported graduates being independent performing intracranial bolt (45.8\%), ventriculostomy (39.0\%), tracheostomy (39.8\%), or gastrostomy $(19.1 \%)$ procedures. Trainees differed from physicians and program directors, respectively, by advocating independence in EEG interpretation (92.8\%, 61.8\%, and 65.3\%) and PEG placement (29.3\%, $9.1 \%$, and $8.5 \%)$.

\section{Conclusions}

Broad support exists across NCC role groups for wide-ranging NCC competencies including skills often performed by other neurology and non-neurology subspecialties. Variations highlight natural divergences in expectations among trainee, physician, and nurse role groups. These results establish expectations for core competencies within NCC and initiate dialogue across subspecialties about best practice standards for the spectrum of critically ill patients requiring neurologic care.

From Tulane University School of Medicine (A.S.C.), New Orleans, LA; Department of Neurology (S.I.), Brigham and Women's Hospital, Boston, MA; Department of Neurology (M.A.K.), University of Pennsylvania, Philadelphia; Department of Public Health Sciences (C.J.J.), Loyola University, Chicago, IL; Departments of Neurology and Neurotherapeutics (S.A.F., C.E.H.) and Anesthesiology, Neurology, and Neurosurgery (D.L.M.), UT Southwestern, Dallas, TX; Department of Neurology (M.B.M.), Northwestern University Feinberg School of Medicine, Chicago, IL; Department of Neurology (D.P.L.), Lahey Clinic, Burlington, MA; Departments of Neurology and Neurosurgery (P.M.V.), David Geffen School of Medicine at UCLA, Los Angeles, CA; Departments of Critical Care Medicine, Neurology \& Neurosurgery (L.A.S.), University of Pittsburgh School of Medicine/UPMC, PA; and Department of Neurology (E.S.R.), Massachusetts General Hospital, Boston.

Go to Neurology.org/N for full disclosures. Funding information and disclosures deemed relevant by the authors, if any, are provided at the end of the article. 


\section{Glossary}

ACGME $=$ Accreditation Council for Graduate Medical Education; DIR = directors of a fellowship or neurosciences intensive care unit; FEL = neurocritical care fellows; ICP = intracranial pressure; ICU = intensive care unit; NCC = neurocritical care; NCS = Neurocritical Care Society; NUR = critical care nurses; PHY = attending physicians; RES = neurology residents; TCD = transcranial Doppler; UCNS = United Council for Neurologic Subspecialties.

Neurocritical care (NCC) is a subspecialty of neurology dedicated to the management of critically ill patients with the most severe manifestations of diverse neurologic and neurosurgical illnesses. Fellowship programs in NCC are accredited by the United Council for Neurologic Subspecialties (UCNS), which promotes a diverse curriculum focused on conditions including cerebrovascular diseases, neurotrauma, epilepsy, neuroinfectious and neuroinflammatory diseases, and other neurologic subspecialty diagnoses. The UCNS curriculum also emphasizes general critical care competencies and a variety of diagnostic and procedural skills ranging from vascular access to placement of ventriculostomy and intracranial monitors, general and transcranial Doppler (TCD) ultrasonography, endotracheal intubation, bronchoscopy, and EEG interpretation. ${ }^{1}$

NCC training programs are open to applicants from multiple specialties in addition to neurology, including neurosurgery, anesthesiology, emergency medicine, internal medicine, pediatrics, and surgery. Despite a near doubling of NCC fellowship training programs over the last 5 years, no organized studies exist to guide the 56 UCNS-accredited programs' curriculum development. ${ }^{2}$ In addition, there is no consensus among NCC fellowship programs on the level of independence expected for specific competencies upon graduation. As with neurohospitalist programs, ${ }^{3}$ the practice of NCC has considerable overlap and collaboration with other neurology subspecialists including vascular neurologists, clinical neurophysiologists, neuromuscular neurologists, and neurosurgeons as well as other medical or surgical intensivists.

In order to clarify the emerging role of NCC physicians within this multidisciplinary landscape, we sought to assess the priorities for training endorsed by neurology residents, NCC fellows in training, NCC fellowship directors and staff physicians, and NCC nurses. We aimed to identify core competencies in NCC training, and describe where the major differences in training priorities may exist.

\section{Methods}

\section{Study design}

A panel of UCNS NCC program directors (S.A.F., C.E.H., M.A.K., D.L.M., P.M.V., L.A.S., and E.S.R.) developed a questionnaire after reviewing UCNS program requirements, core curriculum, and published examination components. ${ }^{2}$ Respondents were asked to indicate the degree to which NCC trainees should achieve independence for specific competencies. We defined "independent at or after graduation" as autonomy at or within a few years of graduation, whereas "not independent at or after graduation" was defined as preferring that graduates never achieve independence or that graduates require help from another specialist.

We prespecified an analysis of responses from all physicians as well as between-group differences in responses from specific role groups: trainees, staff physicians, program directors, and nurses. Although residents may join an NCC fellowship following a variety of residencies, we chose to focus the sampling of trainees to NCC fellows and to neurology residents. As such, we elected not to sample resident trainees in other specialties in this survey, given that their current representation in NCC fellowship programs is not large, their UCNS fellowship training may be 1 year in duration rather than 2 , and their responses may be highly oversampled for those pursuing practices in other fields.

Demographic information such as level of training, years in practice, and institutional information was requested from respondents. The scope of the present analysis was limited to priorities related to training breadth, although the questionnaire also included questions about the preferred methods of evaluating milestones and competency.

The study protocol was reviewed by the local institutional review board and met criteria for exemption based on the survey design and the educational intent of the study.

\section{Data collection}

Upon review and approval by the Neurocritical Care Society (NCS), the survey was posted on the NCS website and disseminated to its physician and nursing members in multiple NCS announcements. In addition, the survey was comprehensively disseminated by Accreditation Council for Graduate Medical Education (ACGME) neurology residency program directors and UCNS NCC fellowship program directors to trainees, physicians, and nurses based on program registration information from the UCNS Fellowship Training Program directory $^{2}$ and the ACGME directory of neurology residency programs. ${ }^{4}$ Program directors were asked to send the survey to their residents and fellows and to distribute to nurse leaders at their institutions. In total, program directors at over 90 institutions in 37 states were contacted.

Survey responses were collected and managed using the REDCap (Research Electronic Data Capture) ${ }^{5}$ electronic database. Participants were offered the opportunity to enter a raffle, utilizing a code generated automatically upon completion of the survey. 


\section{Statistical analysis}

Statistical significance of differences across role groups was determined with $\chi^{2}$ or Fisher exact tests, as appropriate, in SAS 9.4 (Cary, NC). Survey questions that did not have at least one answer selected were omitted from analysis. Due to the hypothesis-generating nature of this study, we did not correct for multiple comparisons.

\section{Results}

A total of 268 providers from 30 institutions participated: 74 (27.6\%) neurology residents (RES), 31 (11.6\%) NCC fellows (FEL), 46 (17.2\%) attending physicians (PHY), 60 (22.4\%) directors of a fellowship or neurosciences intensive care unit (DIR), 32 (11.9\%) critical care nurses (NUR), 13 (4.9\%) nurse practitioners or physician assistants, and $12(4.5 \%)$ others. Among respondents, 96.5\% were from academic medical centers, $93.3 \%$ were from institutions with a neurosciences intensive care unit (ICU), and $77.4 \%$ were from an institution with an NCC fellowship training program. Of the 211 physicians, 38.9\% were certified in NCC through the UCNS practice or fellowship track and $88.2 \%$ had trained in a neurology residency. The remainder of physician respondents trained in internal medicine (4.7\%), emergency medicine (2.4\%), anesthesiology (1.9\%), surgical critical care $(1.0 \%)$, and medicine-psychiatry (1.0\%) residencies.

Overall $>90 \%$ of respondents endorsed NCC graduates demonstrating independence in clinical localization, interpreting and managing systemic and cerebral hemodynamic data, performing brain death determination, neurovascular ultrasound, vascular access, and airway management. Over $75 \%$ supported graduates being independent in performing bronchoscopy, interpreting EEG, and cerebral angiography. Fewer respondents expressed support for graduates performing intracranial bolt (45.8\%), tracheostomy (39.8\%), ventriculostomy (39.0\%), or gastrostomy $(19.1 \%)$ procedures (figure 1$)$.

An analysis of the differences in these priorities among provider roles is shown in table e-1 (links.lww.com/WNL/ A521). For all procedural competencies, trainees more often supported the need for graduates to develop independence. Significant differences among role groups were identified in support for independence in performing several procedures. Trainees (RES and FEL respondents) advocated for greater independence for EEG interpretation than PHY or DIR (92.8\% vs $61.8 \%$ vs $65.3 \% ; p<0.001)$. A higher percentage of trainees and PHY believed tracheostomy placement was more important than did DIR ( $48.2 \%$ vs $41.2 \%$ vs $24.5 \%$; $p=$ 0.027). Significantly more trainee respondents believed that proficiency in PEG placement was necessary, whereas fewer than $10 \%$ of PHY and DIR gave this response $(29.3 \%$ vs $9.1 \%$ vs $8.5 \%$; $p=0.004$ ). The opinions of the RES, FEL, and DIR groups differed significantly from those of $\mathrm{PHY}$, where the former endorsed greater support for independence in performing intubation and airway management and interpreting cerebral angiography ( $p=0.012$ and $p<0.001$, respectively). For diagnostic competencies (volume status assessment, interpretation of intracranial pressure [ICP], interpretation of

Figure 1 Skills and competencies in which a fellow should demonstrate independence by graduation among all physician respondents

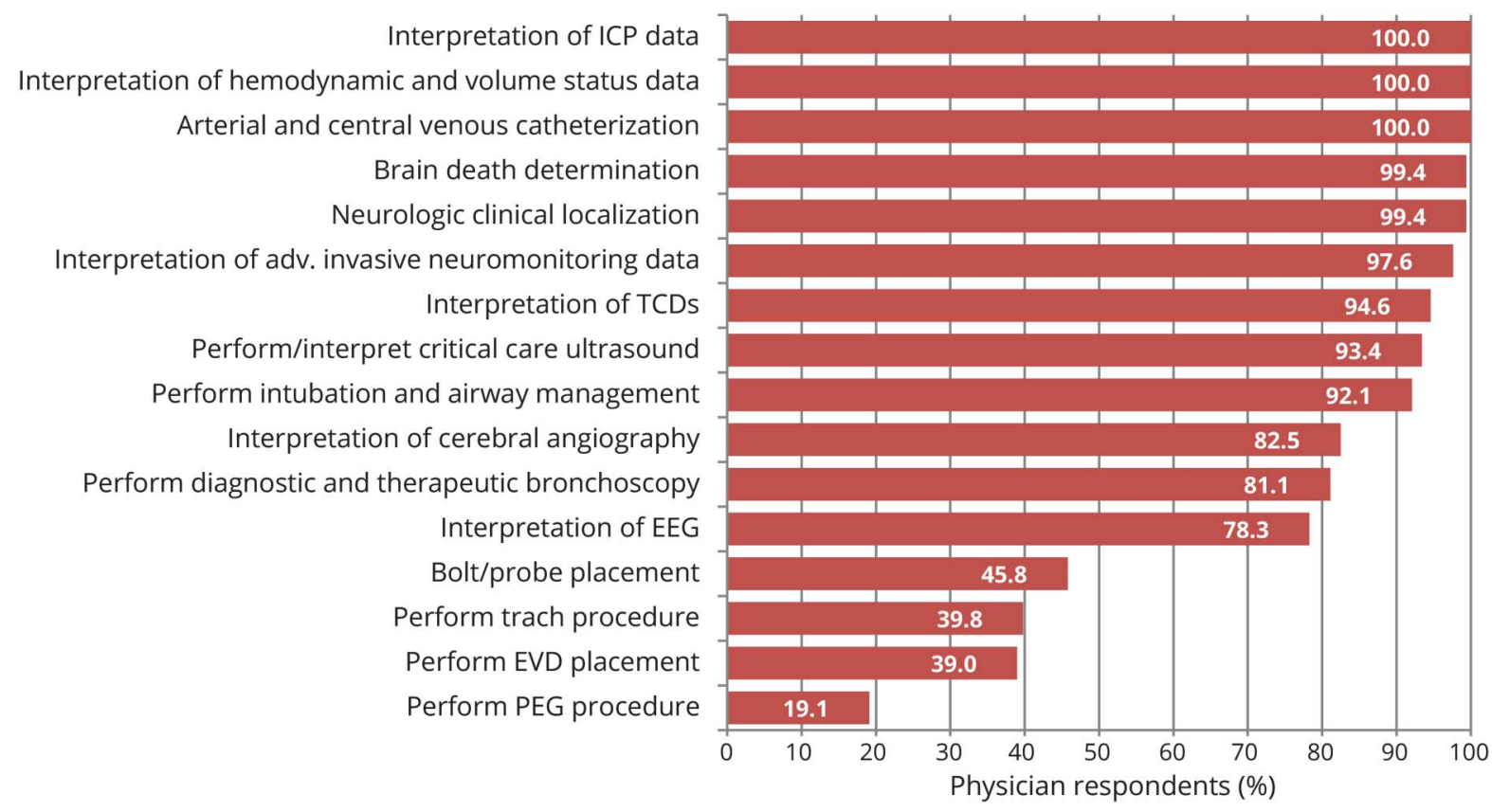

EVD = external ventricular drain; ICP = intracranial pressure; $P E G=$ percutaneous endoscopic gastrostomy; $T C D=$ transcranial Doppler. 
advanced invasive neuromonitoring, interpretation of TCD, brain death evaluation, and clinical localization), competency of fellowship graduates was strongly supported by all role groups. A subgroup analysis revealed no significant difference between RES and FEL responses for questions about training priorities $(p>0.15)$, except for diagnostic and therapeutic bronchoscopy, in which FEL more frequently endorsed the goal of independence vs RES among respondents (96.4\% vs $78.2 \%$, respectively; $p=0.051$ ).

The recommended duration of rotations within a 2-year fellowship was similar across role groups (figure 2). For the amount of time dedicated to mentored research, trainees and directors recommended a similar percentage of time RES (14.5\%), FEL (16.3\%), and directors (14.9\%); however, PHY recommended less (10.7\%) and nurses substantially less (5.0\%). NUR advocated for greater time spent in the neuroscience ICU setting (59.5\%) as compared to physician respondents (RES 46.0\%, FEL 48.6\%, PHY 49.5\%, and DIR $51.2 \%)$. NUR also favored more time allotted for emergency department/stroke than other role groups.

\section{Discussion}

This study details the priorities of NCC trainees, nurses, and physicians for fellowship training competencies, and details which competencies enjoy broad consensus among role groups as well as where viewpoints diverge. The results demonstrate near unanimity that NCC fellowship graduates should achieve independence in core competencies including interpretation of invasive and noninvasive hemodynamic monitoring, advanced neuromonitoring data, and clinical neurologic examination as well as proficiency in routine critical care procedures including vascular access and airway management procedures.

Support across role groups, however, extends beyond these core neurologic skills; an overwhelming majority of trainees endorse independence in skills pertaining to other neurology subspecialties as well as anesthesiology, pulmonology, and other critical care specialties. Nearly half of respondents asserted that NCC graduates should be independent in placing intracranial monitors, a skill historically performed by neurosurgeons. A large minority even endorse training fellows

Figure 2 Recommended duration of rotations during fellowship

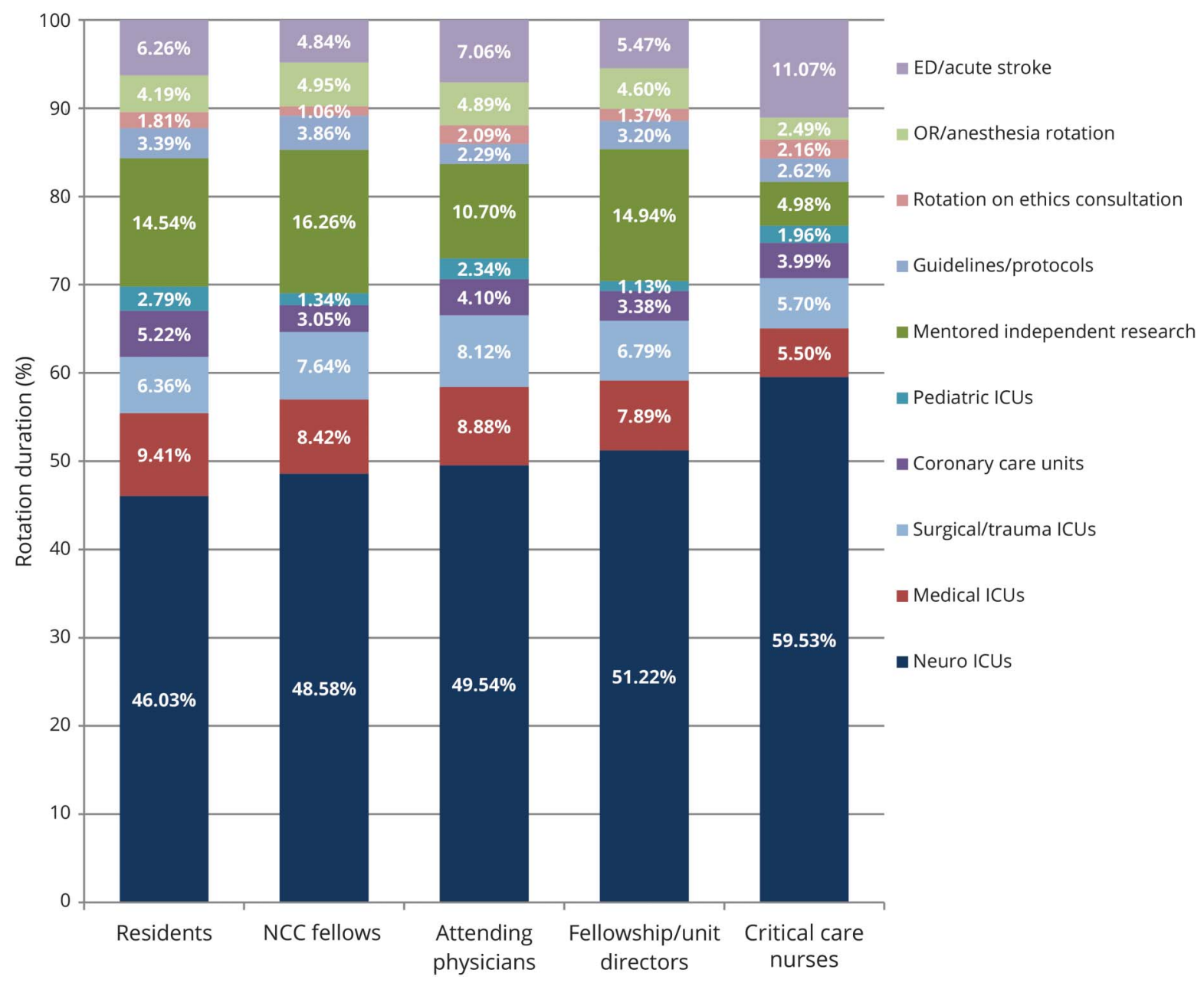

ED = emergency department; ICU = intensive care unit; NCC = neurocritical care; OR = operating room. 
to become independent in performing tracheostomy and gastrostomy procedures, although results varied among NCC role groups.

Discrepancies between established physicians and trainees may reflect factors including recent trends in practice, idealized vs pragmatic views of case mix and volume, biases inherent in oversampling academic centers, awareness of hospital credentialing and risk management, existing stakeholders and routines, and institutional variations in practice such as the contrast between open and closed models of collaborative practice.

Our study has many strengths including good sample size, geographic representation, and diversity of role groups surveyed. The relative dearth of nonacademic respondents may result in a reporting bias that underrepresents competencies of greater relevance to practitioners in nonacademic settings. Moreover, survey respondents may anchor their views based on preexisting practice patterns at each institution. Importantly, trainees from non-neurology backgrounds may have greater baseline competencies in certain domains and relative deficiencies in others, and therefore may value specific competencies differently than physicians from a neurology background who represent the large majorities of survey respondents. However, physicians from nonneurology backgrounds are relatively underrepresented in this study, although this may in some part reflect increase in the likelihood of NCC physician respondents being neurology trained and dramatic increase in the frequency of respondents who work at an institution with a dedicated neurologic ICU. Both these factors have greatly increased compared with a survey distributed in 2011 that showed nearly double the rate of neurology-trained NCC physicians at institutions with a dedicated neurologic ICU. ${ }^{6}$ Accordingly, the survey responses reflect the composition of the trainees responding. However, these shifts may also represent a generational trend in the demand for core critical care skills among fellowship-trained NCC practitioners as well as an increase in fellow-trained NCC practitioners across programs.

The level of training background is another potential study confounder; to address such a limitation, we performed a subgroup analysis of residents' vs fellows' responses and found no statistically significant differences among their responses (not shown). Only one competency, diagnostic and therapeutic bronchoscopy, produced a trend towards a difference between FEL and RES responses, which may relate to familiarity with the performance of this procedure by NCC physicians. Analyses stratifying trainees by their training backgrounds (neurology-trained vs neurosurgery vs anesthesiology vs internal medicine) were not feasible due to the small sample sizes outside of neurology. Finally, these data are based on preferences and opinions rather than data equating training methods with patient outcomes. Future studies may benefit from extending the study to include neurologists in other subspecialties as well as neurosurgeons and medical or surgical intensivists.
Overall, this survey demonstrates that the growth in the number of NCC trainees and practitioners is accompanied by an expansive vision for the practice of NCC physicians, as expressed by neurology residents and other study participants. NCC and other critical care practitioners have historically agreed that NCC units improve the quality of care for patients, and neurology residencies have responded by expanding NCC educational offerings. ${ }^{6,7}$ However, practitioners from different training derivations express differing levels of confidence in the readiness of neurologists to provide critical care. ${ }^{8}$ This survey confirms that practitioners of NCC envision training to include both fundamentals of general critical care (e.g., airway management, bronchoscopy, and critical care ultrasonography) as well as neuroscience-specific skills (e.g., clinical neurophysiology, ICP monitor placement, critical care ultrasonography, and TCD ultrasonography). While there were discordant opinions regarding fellows' required level of independence in certain competencies, the envisioned goal competencies and time allotted to rotations was largely consistent across role groups. This general and widespread agreement may form the basis for future curriculum recommendations for NCC training programs. Where viewpoints of role groups diverge, this study demonstrates the importance of incorporating diverse representation into workgroups developing recommendations for NCC curriculum standards, both to accurately meet changes in training and to empower program directors when seeking institutional support to specify training goals.

\section{Author contributions}

Abigail S. Cohen: drafting/revising the manuscript, study concept and design, analysis or interpretation of data, accepts responsibility for conduct of research and final approval, acquisition of data, statistical analysis. Saef Izzy: drafting/revising the manuscript, study concept and design, accepts responsibility for conduct of research and final approval, acquisition of data, study supervision. Monisha A. Kumar: drafting/revising the manuscript, analysis or interpretation of data, accepts responsibility for conduct of research and final approval, statistical analysis. Cara J. Joyce: drafting/revising the manuscript, analysis or interpretation of data, accepts responsibility for conduct of research and final approval, statistical analysis. Stephen A. Figueroa: drafting/revising the manuscript, study concept or design, accepts responsibility for conduct of research and final approval, study supervision. Matthew B. Maas: drafting/ revising the manuscript, analysis or interpretation of data, accepts responsibility for conduct of research and final approval. Christiana E. Hall: drafting/revising the manuscript, study concept or design, accepts responsibility for conduct of research and final approval. David L. McDonagh: drafting/revising the manuscript, study concept or design, accepts responsibility for conduct of research and final approval. David P. Lerner: drafting/revising the manuscript, analysis or interpretation of data, accepts responsibility for conduct of research and final approval. Paul M. Vespa: drafting/revising the manuscript, study concept or design, accepts responsibility for conduct of research and final approval, acquisition of data, study 
supervision. Lori A. Shutter: drafting/revising the manuscript, study concept or design, analysis or interpretation of data, accepts responsibility for conduct of research and final approval. Eric S. Rosenthal: drafting/revising the manuscript, study concept and design, analysis and interpretation of data, accepts responsibility for conduct of research and final approval, acquisition of data, study supervision, obtaining funding.

\section{Study funding}

No targeted funding reported.

\section{Disclosure}

The authors report no disclosures relevant to the manuscript. Go to Neurology.org/N for full disclosures.

\section{References}

1. Neurocritical care core curriculum. Available at: ucns.org/globals/axon/assets/3656.pdf. Accessed June 8, 2015.

2. Neurocritical care. Available at: ucns.org/go/subspecialty/neurocritical. Accessed June 8, 2015 .

3. Josephson SA, Engstrom JW, Wachter RM. Neurohospitalists: an emerging model for inpatient neurological care. Ann Neurol 2008;63:135-140.

4. Accreditation Council for Graduate Medical Education (ACGME). Available at: https://apps.acgme.org/ads/Public/Programs/Search. Accessed May 1, 2018.

5. Harris PA, Taylor R, Thielke R, et al. Research electronic data capture (REDCap): a metadata-driven methodology and workflow process for providing translational research informatics support. J Biomed Inform 2009;42:377-381.

6. Sheth KN, Drogan O, Manno E, Geocadin RG, Ziai W. Neurocritical care education during neurology residency: AAN survey of US program directors. Neurology 2012; 78:1793-1796.

7. Da Silva IR, Gomes JA. Residency training: the role of neurocritical care in resident education. Neurology 2013;80:e51-e53.

8. Markandaya M, Thomas KP, Jahromi B, et al. The role of neurocritical care: a brief report on the survey results of neurosciences and critical care specialists. Neurocrit Care 2012;16:72-81.

\section{Subspecialty Alerts by E-mail!}

Customize your online journal experience by signing up for e-mail alerts related to your subspecialty or area of interest. Access this free service by clicking on the "My Alerts" link on the home page. An extensive list of subspecialties, methods, and study design choices will be available for you to choose from-allowing you priority alerts to cutting-edge research in your field!

\section{AAN Wants to Help You with MIPS!}

MACRA and the Quality Payment Program and the 2018 Merit-based Incentive Payment System (MIPS) performance year began January 1. The AAN is committed to your success and has tools and resources to help you successfully meet your performance goals with minimal amount of effort. Take action today and visit AAN.com/view/QPP or email your questions to macra@aan.com.

\section{The AAN Has Your Back!}

Every day, the AAN is fighting for you. From actively lobbying members of Congress for common sense legislation, to meeting with regulators to demonstrate the value of neurology and reduce regulatory hassles, the Academy is forcefully countering any threats to your profession and patient access to care. Learn more at AAN.com/policy-and-guidelines/advocacy, read the bimonthly Capitol Hill Report and monthly AANnews member magazine, and respond to Advocacy Action Alert emails when we invite you to share your voice with Congress.

Get into the conversation at \#AANAdvocacy. 


\section{Neurology}

\section{Education Research: Variation in priorities for neurocritical care education expressed across role groups}

Abigail S. Cohen, Saef Izzy, Monisha A. Kumar, et al. Neurology 2018;90;1117-1122

DOI 10.1212/WNL.0000000000005682

\section{This information is current as of June 11, 2018}

\section{Updated Information \& Services}

References

Subspecialty Collections

Permissions \& Licensing

Reprints including high resolution figures, can be found at: http://n.neurology.org/content/90/24/1117.full

This article cites 5 articles, 2 of which you can access for free at: http://n.neurology.org/content/90/24/1117.full\#ref-list-1

This article, along with others on similar topics, appears in the following collection(s):

\section{All Education}

http://n.neurology.org/cgi/collection/all_education EEG

http://n.neurology.org/cgi/collection/eeg

Models of care

http://n.neurology.org/cgi/collection/models_of_care

\section{Ultrasound}

http://n.neurology.org/cgi/collection/ultrasound

Information about reproducing this article in parts (figures,tables) or in its entirety can be found online at:

http://www.neurology.org/about/about_the_journal\#permissions

Information about ordering reprints can be found online:

http://n.neurology.org/subscribers/advertise

Neurology ${ }^{\circledR}$ is the official journal of the American Academy of Neurology. Published continuously since 1951, it is now a weekly with 48 issues per year. Copyright @ 2018 American Academy of Neurology. All rights reserved. Print ISSN: 0028-3878. Online ISSN: 1526-632X.

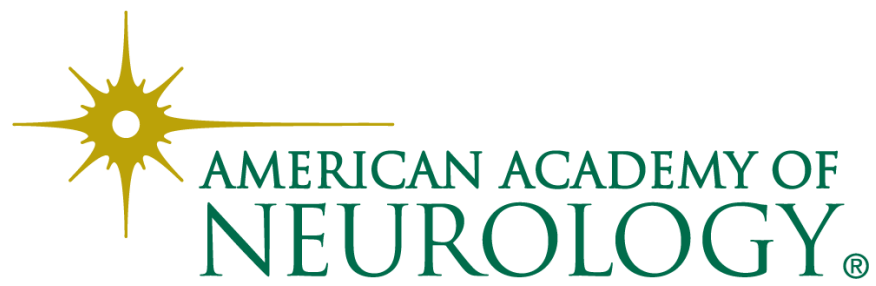

